\title{
Modeling and Numerical Simulation of Fatigue Crack Growth in Cracked Specimens Containing Material Discontinuities
}

\author{
Azher Jameel $^{\mathrm{a}, 1}$ and G. A. Harmain ${ }^{\mathrm{b}}$ \\ a School of Mechanical Engineering, Shri Mata Vaishno Devi University, Katra, India \\ ${ }^{\mathrm{b}}$ Department of Mechanical Engineering, National Institute of Technology, Srinagar, India \\ 1 jameelazher@gmail.com
}

УДК 539.4

\section{Прогнозирование и численное моделирование роста усталостной трещины в образцах с нарушением сплошности материала}

\author{
Ажер Джамил, ${ }^{a}$ Г. А. Хармен ${ }^{6}$ \\ a Механико-машиностроительный факультет, Университет Шри Мата Вайшно Деви, Катра, \\ Индия \\ б Механико-машиностроительный факультет, Национальный технологический институт, \\ Сринагар, Индия
}

Использован расширенный метод конечных элементов для оценки усталостной долговечности образиов с исходной трещиной при наличии биматериальных интерфейсов. Проведена модификация стандартного метода конечных элементов, позволяющая учитывать влияние нарушений сплошности материала в исследуемом объеме с помошью методики уровневого набора. С применением интегрального подхода рассчитаны коэффициенты интенсивности напряжений. Для демонстрации эффекта влияния биматериальных интерфейсов на рост усталостной трещины выполнено численное моделирование нескольких типичных случаев.

Ключевые слова: расширенный метод конечных элементов, наборы уровней, коэффициент интенсивности напряжений, усталостная долговечность, трещины, биматериальные интерфейсы.

Introduction. The modeling and simulation of fatigue crack growth problems are very important to ensure the safety and reliability of various structural components under cyclic loading conditions. Different types of defects and irregularities may develop in the structural components either at the manufacturing stage or during operation. Therefore, it becomes very important to predict the fatigue life of cracked specimens in presence of these defects and irregularities. Over the past few decades, a large number of numerical methods have been developed to model and simulate crack growth problems such as the boundary element method [1-3], the finite element method [4], mesh free methods [5-8] and the extended finite element method (XFEM) [9, 10]. The finite element method has been the most powerful and efficient tool for solving various problems in computational solid mechanics but the modeling of crack growth problems in FEM is quite cumbersome because it requires the mesh to conform to the geometry of the crack surface. This creates huge problems while modeling crack propagation problems where remeshing of domain is needed after each step.

XFEM is an efficient numerical method to model different discontinuities like holes, cracks or inclusions without requiring the finite element mesh to conform to these 
discontinuities. This method was originally proposed by Belytschko and Black [9]. This method models different types of discontinuities by enriching the conventional displacement based approximation with additional enrichment functions [11]. XFEM has been widely used to solve various fracture mechanics problems involving quasi-static crack growth [12], cohesive crack growth [13-15], fatigue crack propagation [16-18], stationary and growing cracks [19] and three dimensional crack propagation [20,21]. This method has also been successfully applied to the modeling of multiple cracks and crack nucleation problems [22-25], inclusions and holes [26, 27], bi-material problems [28-33], frictional contact problems [34-37], dynamic crack propagation [38-42] and elasto-plastic fracture problems [43-45]. XFEM has also been applied to model various problemsin the field of fluid mechanics [46-51], phase transformations [52-54], piezoelectric materials [55] and complex industrial structures $[56,57]$.

The present paper aims at the modeling and simulation of the fatigue crack propagation in structural components in presence of bi-material discontinuities. Several numerical problems have been solved by XFEM and the standard Paris law is used for computing the fatigue life. The maximum principal stress criterion has been used to predict the direction of crack growth [8]. The domain based interaction integral approach [58] has been used to obtain the stress intensity factors. The fidelity of the code developed in the present study is established by solving a few model problems, whose results are already available in literature [7, 58]. Subsequently, the fatigue crack growth in an edge-cracked plate containing bi-material discontinuities, has been addressed here.

1. XFEM Formulations. XFEM is an efficient and powerful approach to model and simulate various types of discontinuities without requiring the finite element mesh to conform to their geometry. Thus, the discontinuities are modelled independent of the mesh. The standard finite element approximation is modified by enriching it with appropriate additional functions known as enrichment functions, which depend upon the nature of discontinuity present in the domain. Consider a domain $\Omega$ enclosed by the boundary $\Gamma$. The boundary of the domain can further be divided into traction $\left(\Gamma_{t}\right)$ and displacement $\left(\Gamma_{u}\right)$ boundaries, as shown in Fig. 1. A crack surface may be considered as an additional boundary $\left(\Gamma_{c}\right)$ inside $\Omega . t$ and $U$ are the prescribed tractions and displacements, respectively, and $u$ represents the displacement field. The equilibrium equation can be written in a general form as $\nabla \sigma+\mathbf{b}=0$, where $\sigma$ represents the Cauchy stress tensor and $\mathbf{b}$ represents the body force per unit volume. For a linear elastic material, the relationship between stress and strain is given by the Hooke law as $\sigma=\mathbf{D} \varepsilon$, where $\mathbf{D}$ is the Hooke tensor and $\varepsilon$ represents the strain tensor. The equilibrium equation presented above can also be represented as

$$
\int_{\Omega} \sigma: \varepsilon(\mathbf{u}) d \Omega=\int_{\Omega} \mathbf{b u} d \Omega+\int_{\Gamma_{t}} \mathbf{t u} d \Gamma .
$$

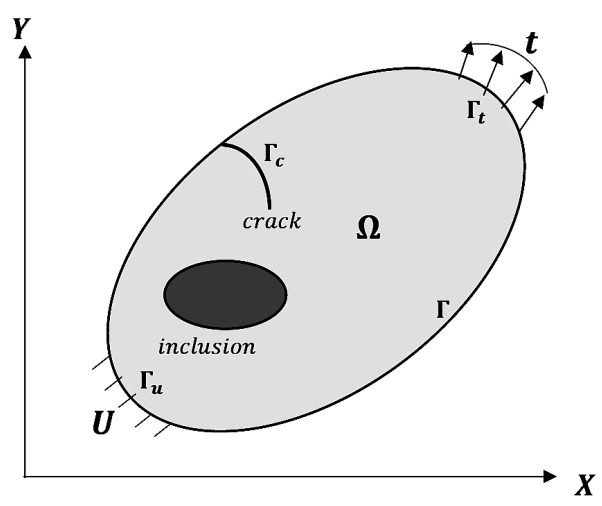

Fig. 1. Domain with crack and inclusion. 
1.1. XFEM Formulation for Cracks. While modeling cracks by XFEM, we come across two types of elements in the domain. The elements that are completely cut by the crack are called split elements and the elements that are partially cut by the crack and contain the crack tip are called tip elements. The modified displacement approximation can be written in general form for modeling crack problems as

$$
\begin{gathered}
u^{h}(x)=\sum_{i=1}^{n} N_{i}(x) u_{i}+\sum_{i=1}^{n_{s}} N_{i}(x)\left[H(x)-H\left(x_{i}\right)\right] a_{i}+ \\
+\sum_{i=1}^{n_{T}} N_{i}(x) \Sigma_{\alpha=1}^{4}\left[\beta_{\alpha}(x)-\beta_{\alpha}\left(x_{i}\right)\right] b_{i}^{\alpha}
\end{gathered}
$$

where $u_{i}$ is the standard nodal degree of freedom, $n$ represents all nodes in the domain, $n_{s}$ denotes the set of split nodes, $n_{T}$ represents the tip nodes, $a_{i}$ denotes the enriched degrees of freedom associated with split elements, $b_{i}^{\alpha}$ denotes the enriched degrees of freedom corresponding to the tip elements, and $N_{i}$ is the standard finite element shape function.

The split nodes are enriched with the Heaviside jump function, $H(x)$. The Heaviside jump function produces a discontinuous displacement field across the crack surface and has a value of +1 on one side and -1 on the other side of the crack surface. The tip elements are enriched with crack-tip enrichment functions, $\beta_{\alpha}(x)$. The crack tip enrichment functions for isotropic elastic problems are defined in local crack tip coordinates $(r$ and $\theta$ ) as given in [59],

$$
\beta_{\alpha}(x)=\left[\sqrt{r} \cos \frac{\theta}{2}, \sqrt{r} \sin \frac{\theta}{2}, \sqrt{r} \cos \frac{\theta}{2} \sin \theta, \sqrt{r} \sin \frac{\theta}{2} \cos \theta\right] .
$$

The second function in the above equation is discontinuous across the crack surface and produces the required discontinuity near the crack tip, while the other three functions are added to improve the accuracy of the results [59]. After substituting the approximate solution of crack [Eq. (2)] in the equilibrium equation, we obtain the final discrete system of equation as $\left[\mathbf{K}^{e}\right]\left\{\mathbf{d}^{e}\right\}=\left\{\mathbf{f}^{e}\right\}$, where $\mathbf{d}^{e}$ is a vector of nodal unknowns defined as $\left\{\mathbf{d}^{e}\right\}=\left\{\begin{array}{llllll}\mathbf{u} & \mathbf{a} & \mathbf{b}_{1} & \mathbf{b}_{2} & \mathbf{b}_{3} & \mathbf{b}_{4}\end{array}\right\}^{T}, \mathbf{K}^{e}$ and $\mathbf{f}^{e}$ are the elemental stiffness matrix and nodal force vector, defined as

$$
\left[\mathbf{K}^{e}\right]=\left[\begin{array}{lll}
\mathbf{K}^{u u} & \mathbf{K}^{u a} & \mathbf{K}^{u b} \\
\mathbf{K}^{a u} & \mathbf{K}^{a a} & \mathbf{K}^{a b} \\
\mathbf{K}^{b u} & \mathbf{K}^{b a} & \mathbf{K}^{b b}
\end{array}\right], \quad\left\{\mathbf{f}^{e}\right\}=\left\{\begin{array}{llllll}
\mathbf{f}^{u} & \mathbf{f}^{a} & \mathbf{f}^{b 1} & \mathbf{f}^{b 2} & \mathbf{f}^{b 3} & \mathbf{f}^{b 4}
\end{array}\right\}^{T} .
$$

In the above equations, the sub-matrices are given by

$$
\mathbf{K}^{r s}=\int_{\Omega^{e}}\left(\mathbf{B}^{r}\right)^{T} \mathbf{D} \mathbf{B}^{s} d \Omega,
$$

where $r, s=u, a, b$,

$$
\begin{gathered}
\mathbf{f}^{u}=\int_{\Omega^{e}} \mathbf{N}^{T} \mathbf{b} d \Omega+\int_{\Gamma^{e}} \mathbf{N}^{T} \mathbf{t} d \Gamma, \\
\mathbf{f}^{a}=\int_{\Omega^{e}} \mathbf{N}^{T}\left(H(x)-H\left(x_{i}\right)\right) \mathbf{b} d \Omega+\int_{\Gamma^{e}} \mathbf{N}^{T}\left(H(x)-H\left(x_{i}\right)\right) \mathbf{t} d \Gamma,
\end{gathered}
$$


$\mathbf{f}^{b \alpha}=\int_{\Omega^{e}} \mathbf{N}^{T}\left(\beta_{\alpha}(x)-\beta_{\alpha}\left(x_{i}\right)\right) \mathbf{b} d \Omega+\int_{\Gamma^{e}} \mathbf{N}^{T}\left(\beta_{\alpha}(x)-\beta_{\alpha}\left(x_{i}\right)\right) \mathbf{t} d \Gamma(\alpha=1,2,3,4)$.

The $B$-matrix relating the strains with displacements is defined as $\left\{\varepsilon^{e}\right\}=[\mathbf{B}]\left\{\mathbf{d}^{e}\right\}$, where $\left\{\varepsilon^{e}\right\}$ represents the strain tensor. The $B$-matrix can be further obtained as

$$
\begin{gathered}
\mathbf{B}^{u}=\left[\begin{array}{cc}
N_{i, x} & 0 \\
0 & N_{i, y} \\
N_{i, y} & N_{i, x}
\end{array}\right], \\
\mathbf{B}^{a}=\left[\begin{array}{cc}
\left(N_{i}\left(H(x)-H\left(x_{i}\right)\right)\right)_{, x} & 0 \\
0 & \left(N_{i}\left(H(x)-H\left(x_{i}\right)\right)\right)_{, y} \\
\left(N_{i}\left(H(x)-H\left(x_{i}\right)\right)\right)_{, y} & \left(N_{i}\left(H(x)-H\left(x_{i}\right)\right)\right)_{, x}
\end{array}\right], \\
\mathbf{B}^{b \alpha}=\left[\begin{array}{cc}
\left(N_{i}\left(\beta_{\alpha}(x)-\beta_{\alpha}\left(x_{i}\right)\right)\right)_{, x} & \left(N_{i}\left(\beta_{\alpha}(x)-\beta_{\alpha}\left(x_{i}\right)\right)\right)_{, y} \\
0 & \left(N_{i}\left(\beta_{\alpha}(x)-\beta_{\alpha}\left(x_{i}\right)\right)\right)_{, x}
\end{array}\right] .
\end{gathered}
$$

1.2. XFEM Formulation for Bi-Material Interfaces. The discontinuities produced by the bi-material interfaces have been modeledthe using the following enrichment function $[60,61]$ :

$$
F(x)=\Sigma_{i}\left|\phi_{i}\right| N_{i}(x)-\left|\Sigma_{i} \phi_{i} N_{i}(x)\right| .
$$

After substituting the approximation functions into the equilibrium equation, we finally obtain the discrete system of equations as $\left[\mathbf{K}^{e}\right]\left\{\mathbf{d}^{e}\right\}=\left\{\mathbf{f}^{e}\right\}$, where $\mathbf{d}^{e}$ is a vector of nodal unknowns, $\mathbf{K}^{e}$ and $\mathbf{f}^{e}$ are the elemental stiffness matrix and nodal force vector, defined as

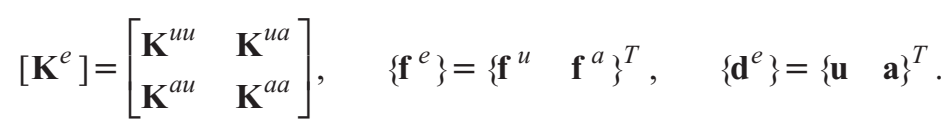

The sub-matrices that appear in the above equations are given by

$$
\mathbf{K}^{r s}=\int_{\Omega^{e}}\left(\mathbf{B}^{r}\right)^{T} \mathbf{D B}^{s} d \Omega
$$

where $r, s=u, a$,

$$
\begin{gathered}
\mathbf{f}^{u}=\int_{\Omega^{e}} \mathbf{N}^{T} \mathbf{b} d \Omega+\int_{\Gamma^{e}} \mathbf{N}^{T} \mathbf{t} d \Gamma, \\
\mathbf{f}^{a}=\int_{\Omega^{e}} \mathbf{N}^{T}\left(F(x)-F\left(x_{i}\right)\right) \mathbf{b} d \Omega+\int_{\Gamma^{e}} \mathbf{N}^{T}\left(F(x)-F\left(x_{i}\right)\right) \mathbf{t} d \Gamma, \\
\mathbf{B}^{u}=\left[\begin{array}{cc}
N_{i, x} & 0 \\
0 & N_{i, y} \\
N_{i, y} & N_{i, x}
\end{array}\right], \quad \mathbf{B}^{a}=\left[\begin{array}{cc}
\left(N_{i}\left(F(x)-F\left(x_{i}\right)\right)\right)_{, x} & 0 \\
0 & \left(N_{i}\left(F(x)-F\left(x_{i}\right)\right)\right)_{, y} \\
\left(N_{i}\left(F(x)-F\left(x_{i}\right)\right)\right)_{, y} & \left(N_{i}\left(F(x)-F\left(x_{i}\right)\right)\right)_{, x}
\end{array}\right] .
\end{gathered}
$$




\section{Fatigue Crack Growth Analysis.}

2.1. Computation of Stress Intensity Factors. In the present study, the domain based integral approach [62-64] has been used to compute the stress intensity factors (SIF) in mixed mode fracture mechanics problems. For any two equilibrium states of a cracked specimen, the domain based interaction integral can be defined as

$$
M^{(1,2)}=\int_{A}\left[\sigma_{i j}^{(1)} \frac{\partial u_{i}^{(2)}}{\partial x_{1}}+\sigma_{i j}^{(2)} \frac{\partial u_{i}^{(1)}}{\partial x_{1}}-W^{(1,2)} \delta_{i j}\right] \frac{\partial q}{\partial x_{j}} d A,
$$

where $q$ is a smooth weight function, whose value is 1 at the crack tip and 0 along the contour, $W^{(1,2)}$ is the mutual strain energy defined as

$$
W^{(1,2)}=\frac{1}{2}\left(\sigma_{i j}^{(1)} \varepsilon_{i j}^{(2)}+\sigma_{i j}^{(2)} \varepsilon_{i j}^{(1)}\right)=\sigma_{i j}^{(1)} \varepsilon_{i j}^{(2)}=\sigma_{i j}^{(2)} \varepsilon_{i j}^{(1)} .
$$

In the above equation, $\sigma$ and $\varepsilon$ represent the stresses and strains, respectively, the states 1 and 2 represent the actual state and the auxiliary state, respectively. The mixed mode stress intensity factors $\left(K_{\mathrm{I}}\right.$ and $\left.K_{\mathrm{II}}\right)$ are related to the interaction integral as

$$
M^{(1,2)}=\frac{2}{E^{*}}\left(K_{\mathrm{I}}^{(1)} K_{\mathrm{I}}^{(2)}+K_{\mathrm{II}}^{(1)} K_{\mathrm{II}}^{(2)},\right.
$$

where $E^{*}=E$ for plane stress and $E^{*}=E /\left(1-\mu^{2}\right)$ for plane strain. The mode-I stress intensity factor is evaluated by choosing $K_{\mathrm{I}}^{(2)}=1, \quad K_{\mathrm{II}}^{(2)}=0$, and for mode-II stress intensity factor, we choose $K_{\mathrm{I}}^{(2)}=0, K_{\mathrm{II}}^{(2)}=1$. Thus, we get $K_{\mathrm{I}}^{(1)}=M^{(1, \mathrm{I})} E^{*} / 2$ and $K_{\mathrm{II}}^{(1)}=M^{(1, \mathrm{II})} E^{*} / 2$.

2.2. Computation of Fatigue Life. The simulation of fatigue crack growth has been carried out by employing the XFEM, under constant amplitude cyclic loading conditions. The stress intensity factor range can be written as $\Delta K=K_{\max }-K_{\min }$, where $K_{\max }$ and $K_{\min }$ represent the maximum and the minimum values of the SIFs, respectively. The present approach models the crack propagation by successive linear crack increments. Several methods have been developed from time to time to predict the direction of crack growth. The present paper employs the maximum principal stress criterion to determine the direction of crack growth. This criterion states that the crack will propagate in the direction perpendicular to maximum principal stress. Thus, the local direction of crack growth $\left(\theta_{c}\right)$ at each crack tip can be obtained by making the local shear stress zero [58], which leads to the following equation:

$$
\theta_{c}=2 \tan ^{-1}\left(\frac{K_{\mathrm{I}}-\sqrt{K_{\mathrm{I}}^{2}+K_{\mathrm{II}}^{2}}}{4 K_{\mathrm{II}}}\right)
$$

Finally, we obtain the equivalent mode-I stress intensity factor as

$$
K_{\mathrm{Ieq}}=K_{\mathrm{I}} \cos ^{3} \frac{\theta_{c}}{2}-3 K_{\mathrm{II}} \cos ^{2} \frac{\theta_{c}}{2} \sin \frac{\theta_{c}}{2} .
$$

After obtaining the equivalent mode-I stress intensity factor, the fatigue life of the component can be obtained by the generalized Paris law defined as $d a / d N=C\left(\Delta K_{\text {Ieq }}\right)^{m}$, 
where $C$ and $m$ are material constants, $a$ represents the crack length, and $N$ is the number of loading cycles. The final failure of the component is assumed to occur when $K_{\text {Ieq }}>K_{\text {Ic } c}$, where $K_{\text {Ic }}$ is the fracture toughness of the material.

3. Numerical Results and Discussions. In this section, several numerical problems have been solved to demonstrate the applicability and efficiency of XFEM in modelling fatigue crack propagation problems in presence of bi-material interfaces. In order to check the accuracy and fidelity of the code developed on XFEM, various model problems have been solved whose results are already available in literature. The present work models the effect of bi-material interfaces on fatigue crack propagation. The effect of the size of bi-material discontinuityon crack growth has been addressed. The effect of the material properties of the circular discontinuity on crack growth is studied. The distance between the crack and the centre of discontinuity is also varied and its effect on fatigue crack propagation is presented in this section. The material properties chosen for analysis are given in Table 1.

$\mathrm{T}$ a b 1 e 1

Material Properties [7, 58]

\begin{tabular}{|c|c|}
\hline Elastic modulus $E, \mathrm{GPa}$ & 74 \\
\hline Elastic modulus for inclusions $E_{i}, \mathrm{GPa}$ & 20 \\
\hline Poisson's ratio (for both) $\mu$ & 0.3 \\
\hline Fracture toughness $K_{\mathrm{Ic}}, \mathrm{MPa} \sqrt{\mathrm{mm}}$ & 1897.36 \\
\hline Paris exponent $m$ & 3.32 \\
\hline Paris constant $C$ & $2.087136 \cdot 10^{-13}$ \\
\hline
\end{tabular}

\subsection{Model Problems for Comparison.}

3.1.1. Inclined Edge Crack [7]. The fatigue crack propagation of an inclined edge crack in a rectangular plate is presented. We use the same material properties, dimensions and loading as in [7] to perform comparison. A rectangular plate of dimensions $100 \times 200 \mathrm{~mm}$ with an inclined edge crack of length $a_{0}=20 \mathrm{~mm}$ is taken for analysis. The crack is inclined at an angle of $40^{\circ}$, as shown in Fig. 2. The plate is subjected to a cyclic tension of $\sigma_{\max }=40 \mathrm{MPa}$ and $\sigma_{\text {min }}=0$ at the top and bottom edges. A uniform mesh of $21 \times 41$ nodes is taken for the sake of analysis. The crack increment $(\Delta a)$ of $5 \mathrm{~mm}$ is taken here. The variation of SIFs with crack length is shown in Fig. 3. The crack length at final failure obtained in this study is $61.78 \mathrm{~mm}$ and the life of the specimen is found to be 162,720 cycles. The results are in good agreement with the results in [7], where the final crack length is $61.3 \mathrm{~mm}$ and the life of the component is 131,411 cycles.

3.1.2. Central Crack in a Rectangular Plate [58]. The fatigue crack growth of a central crack $\left(a_{0}=15 \mathrm{~mm}\right)$ in a rectangular plate $(100 \times 200 \mathrm{~mm})$ is presented in this section. The bottom edge of the plate is fixed while a cyclic tensile load of $\sigma_{\max }=160 \mathrm{MPa}$ and $\sigma_{\min }=0$ is applied at the top edge, as shown in Fig. 4. A uniform mesh of $80 \times 140$ nodes is taken for analysis. The crack increment $(\Delta a)$ of $2 \mathrm{~mm}$ is taken for fatigue crack growth simulation. The variation of SIFs with crack length is shown in Fig. 5. The final crack length of the plate is found to be $56.66 \mathrm{~mm}$ and the life of the plate is found to be 7935 cycles. The results are in very good agreement with the results in [58], where the the life of the component is 7918 cycles and the final crack length is $56.67 \mathrm{~mm}$.

3.2. Effect of Bi-Material Interface on Fatigue Crack Growth. In this section, fatigue crack propagation in specimens containing bi-material discontinuities has been studied. A rectangular plate $(100 \times 200 \mathrm{~mm})$ with an edge crack of length $a_{0}=15 \mathrm{~mm}$ is taken for simulation. The bottom edge of the plate is fixed while a cyclic tensile load of 


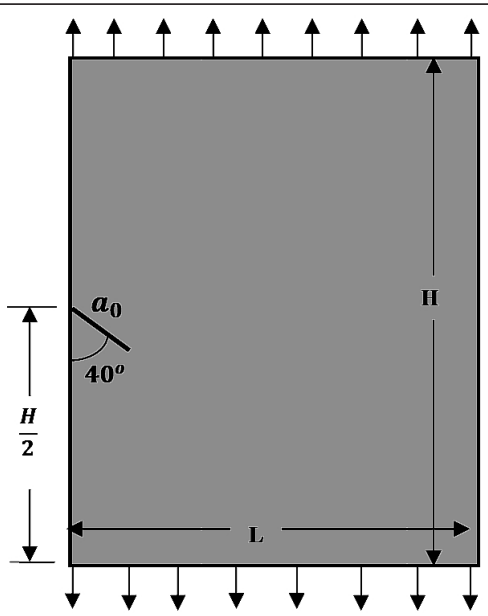

Fig. 2. Plate with the edge crack is inclined at angle of $40^{\circ}$.

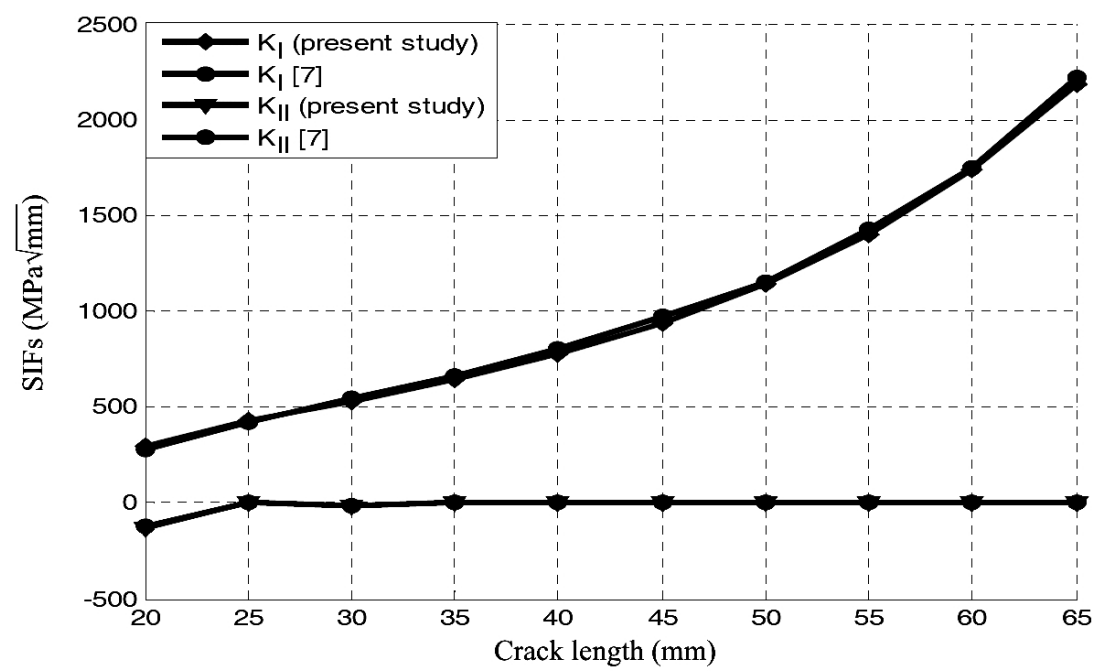

Fig. 3. Variation of stress intensity factors with crack length.

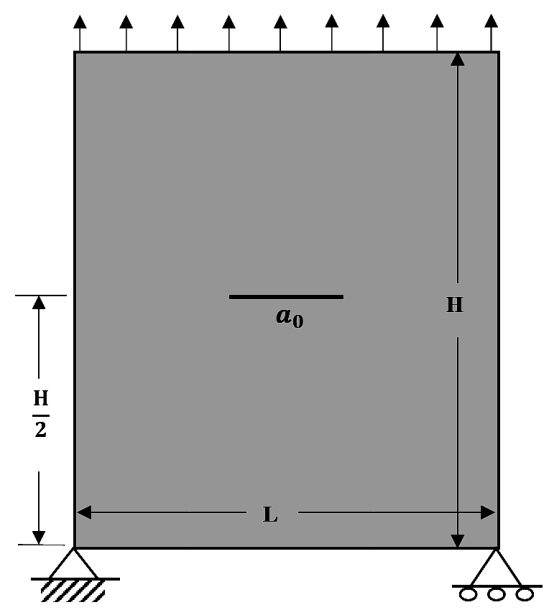

Fig. 4. Plate with the central crack. 


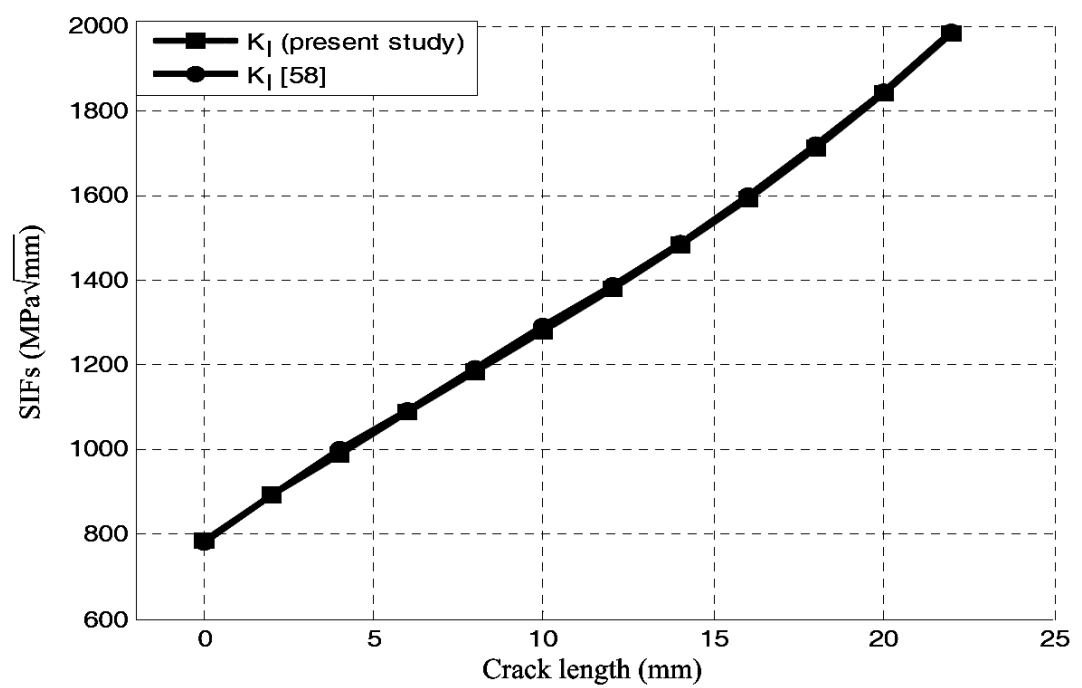

Fig. 5. Variation of stress intensity factors with crack length.

$\sigma_{\max }=60 \mathrm{MPa}$ and $\sigma_{\min }=0$ is applied at the top edge, as shown in Fig. 6. A uniform mesh of $30 \times 60$ nodes is taken for the sake of analysis. The domain has been discretized into four noded Lagrangian type elements. A crack increment of $2 \mathrm{~mm}$ is given at each step of fatigue crack growth until final failure occurs, i.e., $K_{\mathrm{Ieq}}>K_{\mathrm{I} c}$. The fatigue crack growth simulation is carried out in steps, and the stress intensity factor values are evaluated after every step. The stress intensity factors have been evaluated by employing the domain based interaction integral approach, as discussed before. These stress intensity factor values are then used to calculate the fatigue life of the plate using the generalized Paris law. The direction of crack growth has been predicted by using the maximum principal stress criterion, which states that the crack will grow perpendicular to the maximum principal stress.

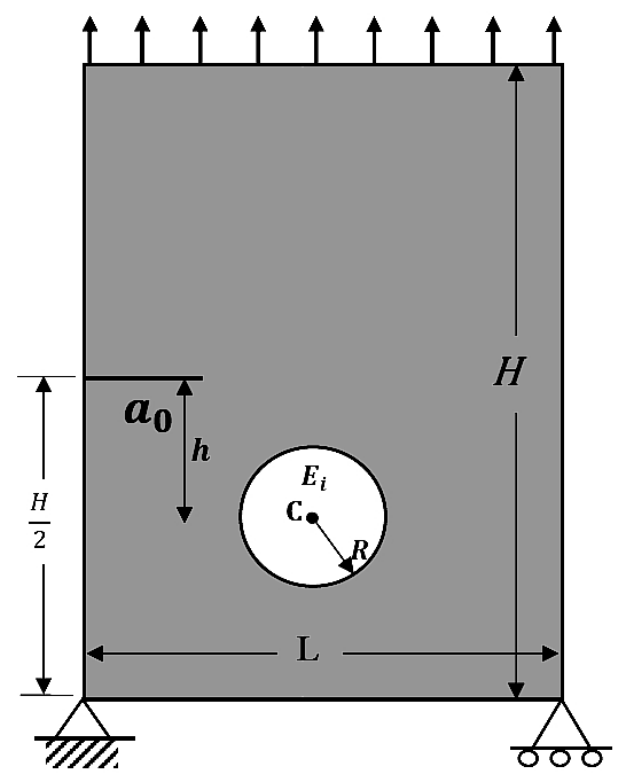

Fig. 6. Plate with a circular bi-material interface. 
3.2.1. Size of Material Discontinuity (R). The effect of the size of discontinuity on crack growth is studied here. The material properties of the discontinuity are assumed to be $E_{i}=20 \mathrm{GPa}$ and $\mu_{i}=0.3$. The centre of the circular discontinuity $\left(x_{c}, y_{c}\right)$ is kept fixed at $x_{c}=50 \mathrm{~mm}$ and $y_{c}=50 \mathrm{~mm}$. The position of the discontinuity remains fixed during crack propagation. The radius of the discontinuity is taken as $5,10,15,20,25,30,35$, and $40 \mathrm{~mm}$. A uniform mesh of $30 \times 60$ nodes is taken for analysis, as shown in Fig. 7. The variation of stress intensity factors with crack length is shown in Fig. 8. The fatigue life diagram is shown in Fig. 9. It has been observed that there is reduction in fatigue life and critical crack length as the size of the weak discontinuity increases. The fatigue life and the critical crack length of the homogenous plate have been found to be 38,010 cycles and $47.52 \mathrm{~mm}$, respectively. The fatigue life and the critical crack length reduce to 10,950 cycles and $39.83 \mathrm{~mm}$, respectively, if there is a discontinuity of radius $40 \mathrm{~mm}$. Finally, the crack growth paths for different discontinuity sizes are shown in Fig. 10. It can be easily seen in Fig. 10, that the weak discontinuity exerts some sort of attractive effect on the crack path during crack propagation.

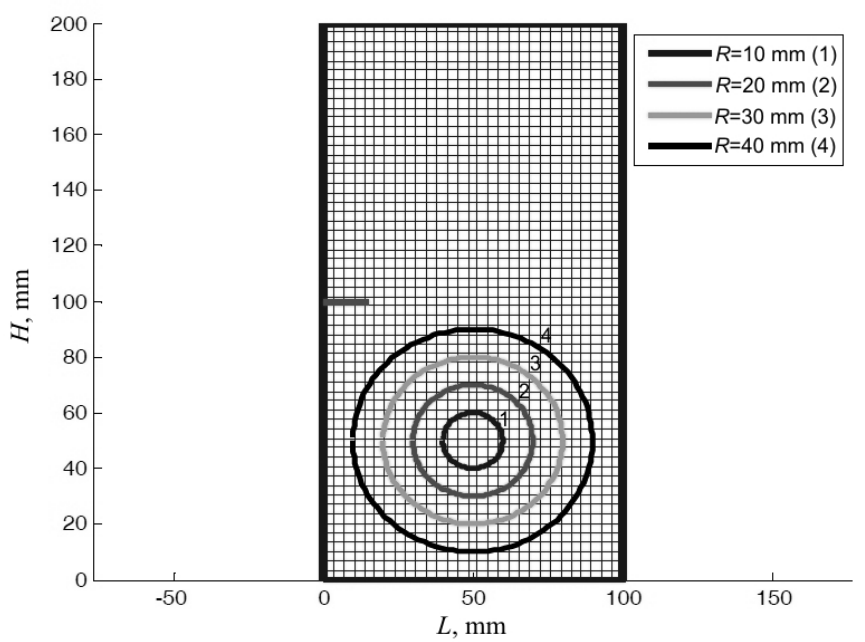

Fig. 7. XFEM mesh for different radii of discontinuities.

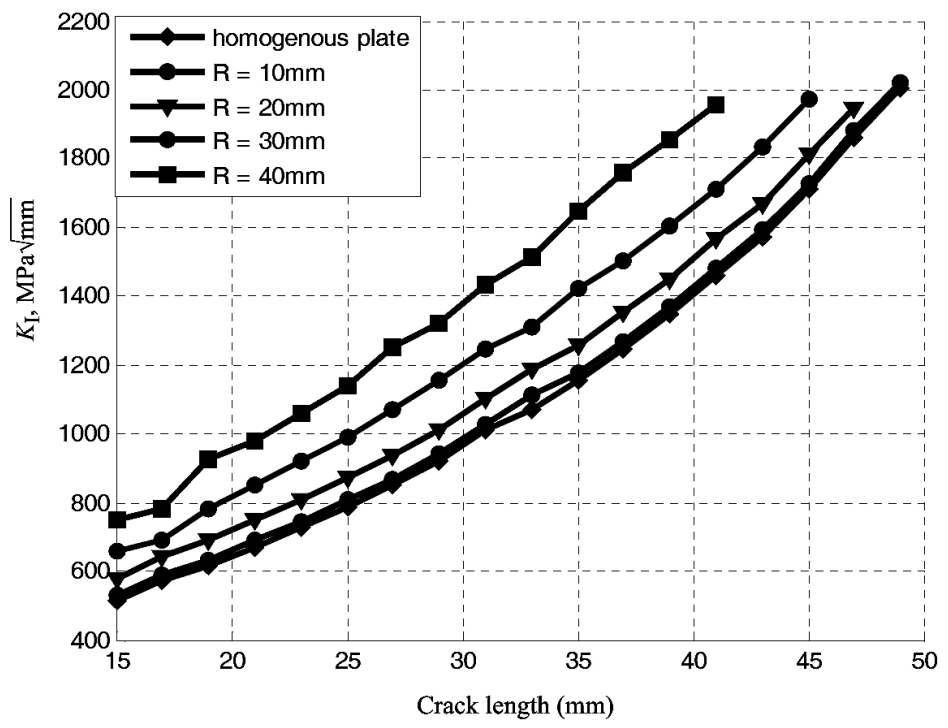

Fig. 8. Variation of stress intensity factors with crack length. 


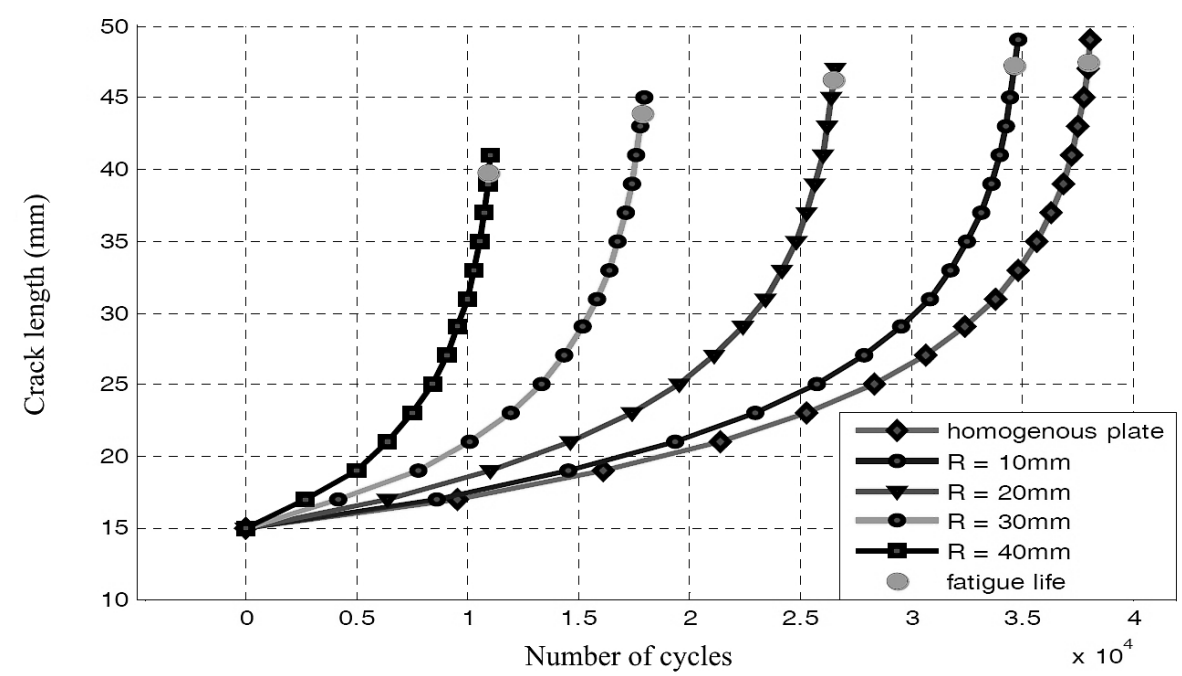

Fig. 9. Fatigue life diagram for different radii of discontinuities.

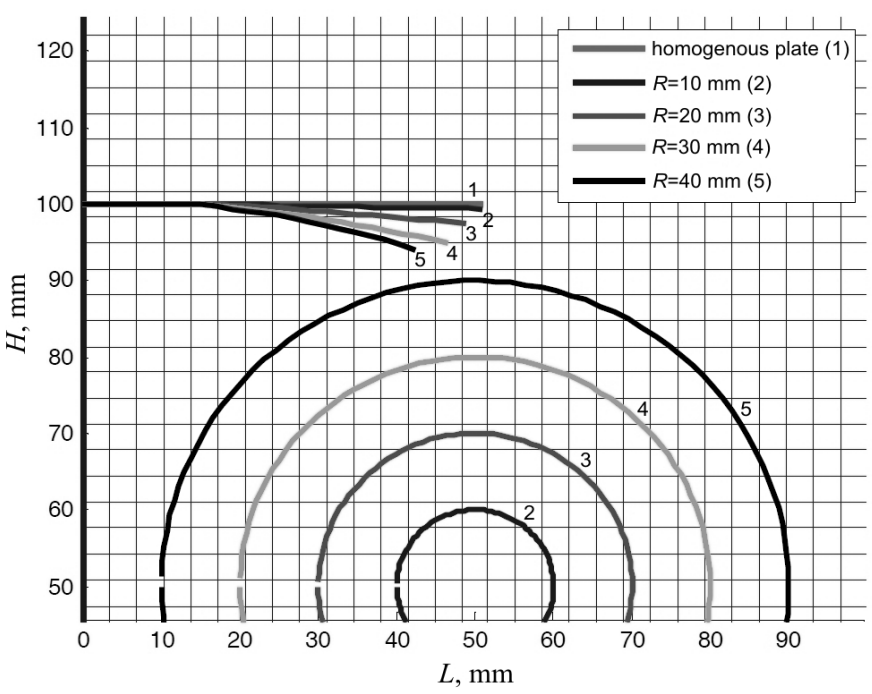

Fig. 10. Crack paths for different radii of discontinuities (zoomed view).

3.2.2. Material Properties of Discontinuity $\left(E_{i}\right)$. The effect of material properties of the discontinuity on fatigue crack propagation is presented here. The radius of the discontinuity is taken to be $20 \mathrm{~mm}$. The centre of the discontinuity $\left(x_{c}, y_{c}\right)$ is kept fixed at $x_{c}=y_{c}=50 \mathrm{~mm}$ and the position of the discontinuity remains fixed during crack propagation. The Young moduli $E_{i}$ of the discontinuity are taken to be 20, 30, 40, 50, 60, $74,80,90,100,110,120$, and $130 \mathrm{GPa}$. The variation of stress intensity factors with crack length is shown in Fig. 11. The fatigue life diagram is presented in Fig. 12. It has been found that the fatigue life and critical crack length increases as the elastic modulus of the discontinuity increases. It can be easily seen that as long as $E_{i}<E$, the crack grows towards the discontinuity and the fatigue life and critical crack length are lower than that of homogenous plate. If $E_{i}>E$, the crack grows away from the discontinuity and the fatigue life and critical crack length are higher than that of homogenous plate. The fatigue life and the critical crack length of the specimen decrease by 30.25 and $2.61 \%$, respectively, for a 


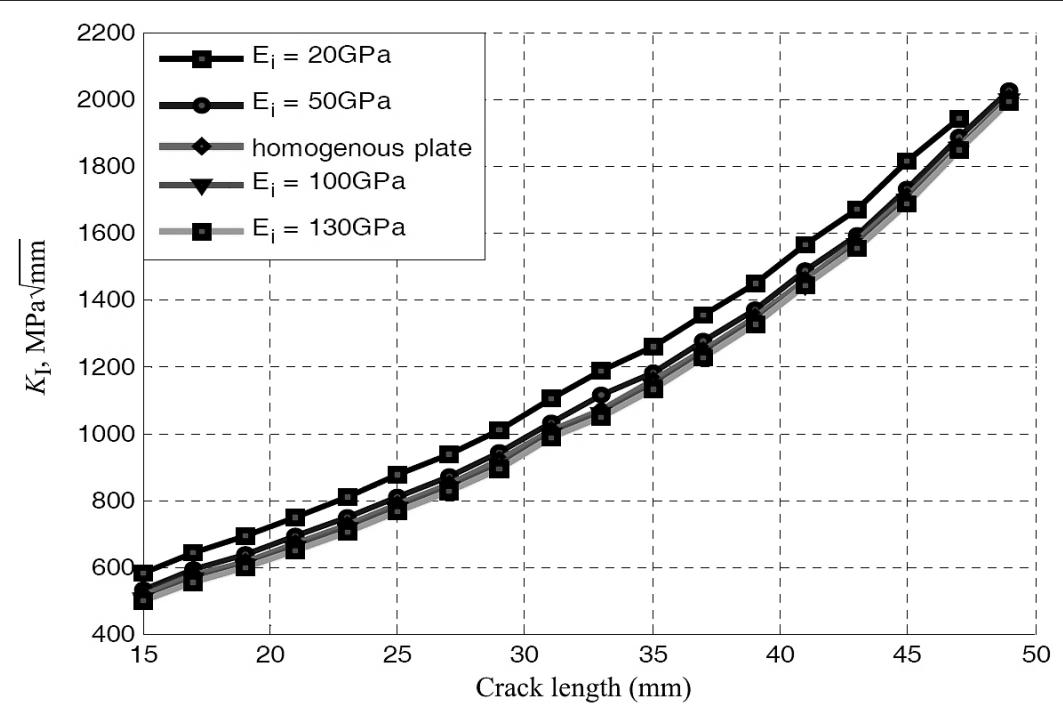

Fig. 11. Variation of stress intensity factors with crack length.

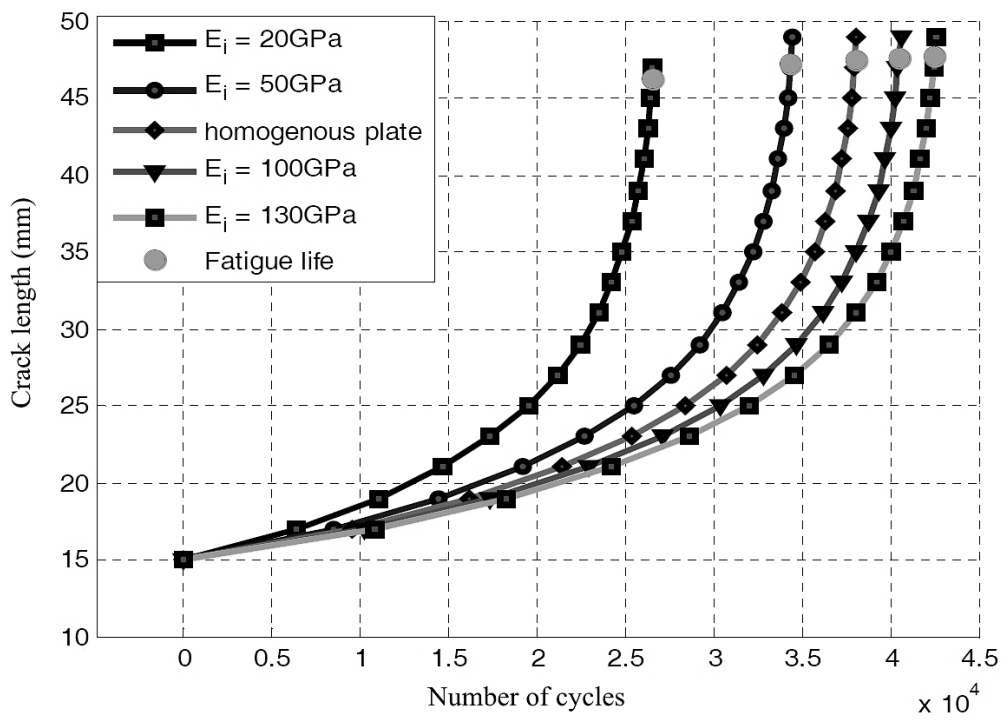

Fig. 12. Fatigue life diagram for different discontinuities.

plate with discontinuity of $E_{i}=20 \mathrm{GPa}$, whereas there is an increase in the fatigue life and critical crack length by 8.41 and $0.29 \%$ for a plate with discontinuity of $E_{i}=110 \mathrm{GPa}$. Finally, Fig. 13 shows the crack paths for different discontinuities.

3.2.3. Distance between Crack and Discontinuity (h). The distance between the center of the discontinuity and the main crack is changed and its effects on the fatigue life of the plate is studied. The material properties of the discontinuity are assumed to be $E_{i}=20 \mathrm{GPa}$ and $\mu_{i}=0.3$. The radius of the discontinuity is taken to be $20 \mathrm{~mm}$. A uniform mesh of $30 \times 60$ nodes is taken for analysis, as shown in Fig. 14. The variation of SIFs with crack is shown in Fig. 15. The fatigue life diagram is shown in Fig. 16. It can be seen that there is reduction in fatigue life and critical crack length as the distance between the crack and the discontinuity decreases. The fatigue life and the critical crack length of the specimen reduce to 19,777 cycles and $42.98 \mathrm{~mm}$, respectively, if the distance between the crack and the 


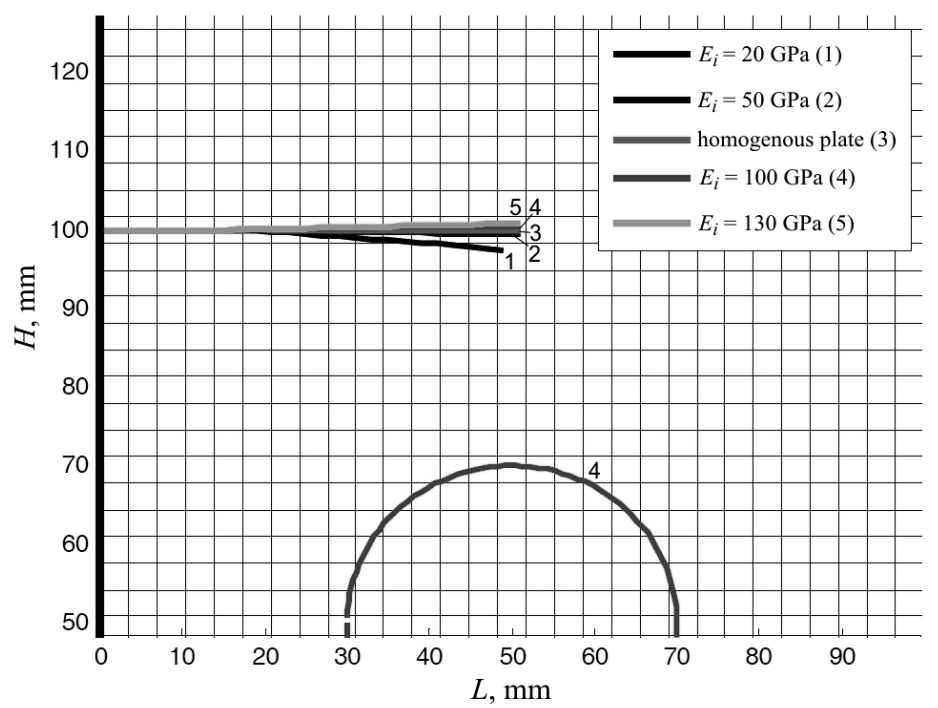

Fig. 13. Crack paths for different discontinuities (zoomed view).

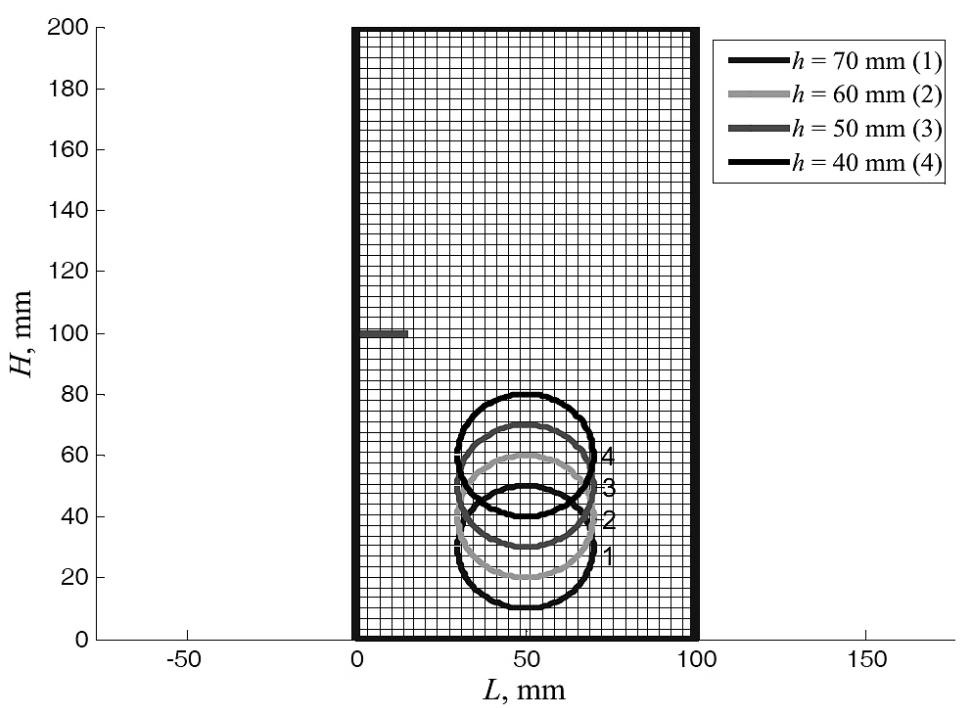

Fig. 14. XFEM mesh for different values of $h$.

discontinuity is $30 \mathrm{~mm}$. The fatigue life and critical crack length reduce by 47.97 and $9.55 \%$, respectively, if the distance between the crack and the discontinuity is $30 \mathrm{~mm}$. Finally, the corresponding crack paths are shown in Fig. 17.

Conclusions. In the present work, XFEM has been applied to solve fatigue crack propagation in specimens containing different types of material discontinuities like bi-material interfaces. The conventional finite element approximation is enriched with appropriate enrichment functions to model different types of discontinuities present in the domain. Several model problems were solved and a remarkable agreement was achieved with the results already available in literature. The results clearly indicate that XFEM can be quite efficiently and accurately used to model and simulate fatigue crack propagation problems in presence of various discontinuities. 


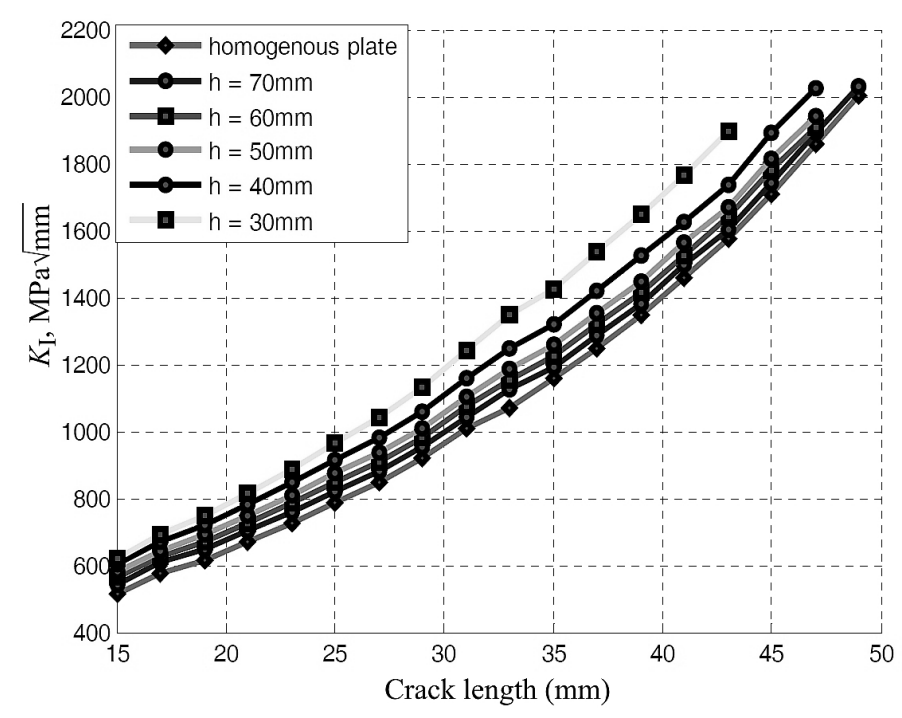

Fig. 15. Variation of stress intensity factors with crack length.

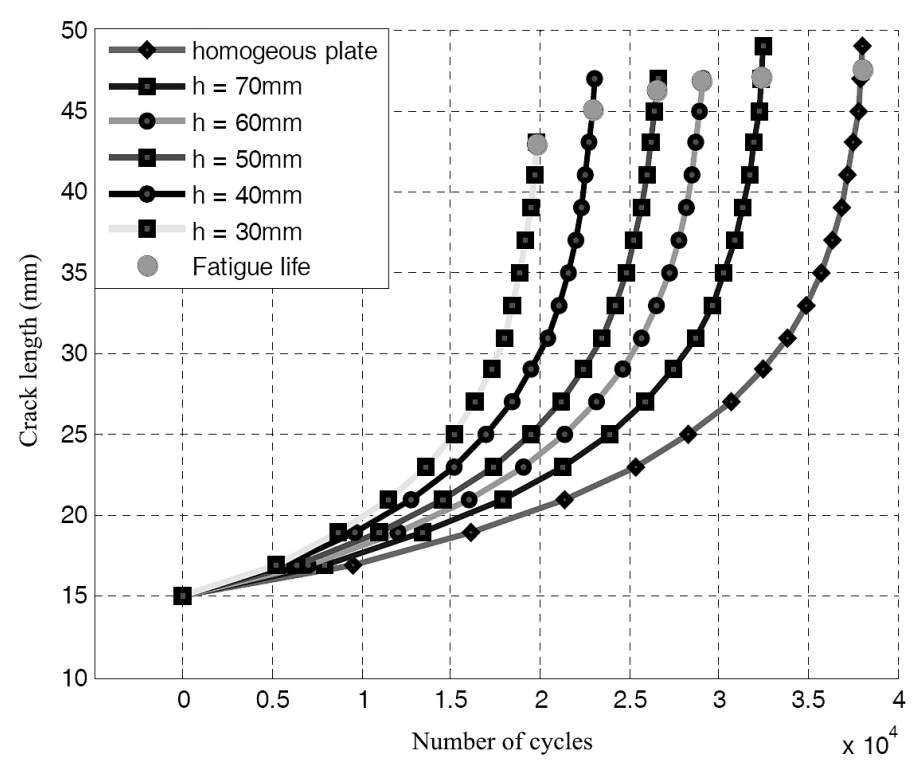

Fig. 16. Fatigue life diagram for different values of $h$.

It was observed that the weak bi-material discontinuity reduces the fatigue life and the critical crack length of the specimen. The results also show the reduction in fatigue life and critical crack length as the size of the weak bi-material discontinuity increases. The decrease in distance between the discontinuity and the crack also reduces the fatigue life of the component. It is also observed that the weaker discontiniuty exerts some sort of a positive effect on the crack path during crack propagation.

\section{Резгме}

Використано розширений метод скінченних елементів для оцінки утомної довговічності зразків із первинною тріщиною за наявності біматеріальних інтерфейсів. 


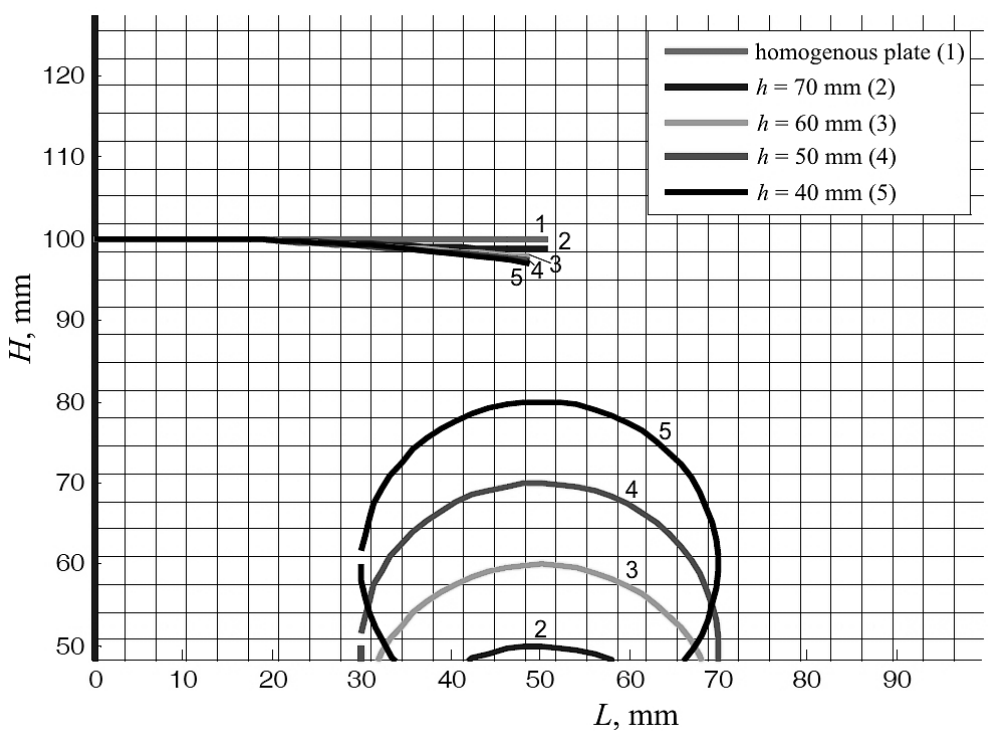

Fig. 17. Crack paths for different values of $h$ (zoomed view).

Проведено модифікацію стандартного методу скінченних елементів, що дозволяє враховувати вплив порушень суцільності матеріалу в досліджуваному об'ємі за допомогою методики рівневого набору. Із використанням інтегрального підходу розраховано коефіцієнти інтенсивності напружень. Для демонстрації ефекту впливу біматеріальних інтерфейсів на ріст тріщини від утомленості виконано числове моделювання декількох типових випадків.

1. A. Portela, M. Aliabadi, and D. Rooke, "The dual boundary element method: effective implementation for crack problem," Int. J. Numer. Meth. Eng., 33, 1269-1287 (1991).

2. A. M. Yan and H. Nguyen-Dang, "Multiple-cracked fatigue crack growth by BEM," Comput. Mech., 16, 273-280 (1995).

3. X. Yan, "A boundary element modeling of fatigue crack growth in a plane elastic plate," Mech. Res. Commun., 33, 470-481 (2006).

4. S. Cheung and A. R. Luxmoore, "A finite element analysis of stable crack growth in an aluminium alloy," Eng. Fract. Mech., 70, 1153-1169 (2003).

5. T. Belytschko, L. Gu, and Y. Y. Lu, "Fracture and crack growth by element-free Galerkin methods," Model. Simul. Mater. Sci. Eng., 2, 519-534 (1994).

6. T. Belytschko, Y. Y. Lu, and L. Gu, "Crack propagation by element-free Galerkin methods," Eng. Fract. Mech., 51, 295-315 (1995).

7. M. Duflot and H. Nguyen-Dang, "A meshless method with enriched weight functions for fatigue crack growth," Int. J. Numer. Meth. Eng., 59, 1945-1961 (2004).

8. M. Duflot and H. Nguyen-Dang, "Fatigue crack growth analysis by an enriched meshless method," J. Comput. Appl. Math., 168, 155-164 (2004).

9. T. Belytschko and T. Black, "Elastic crack growth in finite elements with minimal remeshing," Int. J. Numer. Meth. Eng., 45, 601-620 (1999).

10. C. Daux, N. Moes, J. Dolbow, et al., "Arbitrary branched and intersecting cracks with the extended finite element method," Int. J. Numer. Meth. Eng., 48, 1741-1760 (2000). 
11. J. Dolbow, An Extended Finite Element Method with Discontinuous Enrichment for Applied Mechanics, Ph.D. Thesis, Northwestern University, Evanston, IL (1999).

12. N. Sukumar and J. H. Prevost, "Modeling quasi-static crack growth with the extended finite element method. Part I: Computer implementation," Int. J. Solids Struct., 40, 7513-7537 (2003).

13. G. Zi and T. Belytschko, "New crack-tip elements for XFEM and applications to cohesive cracks," Int. J. Numer. Meth. Eng., 57, 2221-2240 (2003).

14. J. F. Unger, S. Eckardt, and C. Könke, "Modelling of cohesive crack growth in concrete structures with the extended finite element method," Comput. Meth. Appl. Mech. Eng., 196, 4087-4100 (2007).

15. J. L. Asferg, P. N. Poulsen, and L. O Nielsen, "A consistent partly cracked XFEM element for cohesive crack growth," Int. J. Numer. Meth. Eng., 72, 464-485 (2007).

16. J. Qian and A. Fatemi, "Mixed mode fatigue crack growth: a literature survey," Eng. Fract. Mech., 55, No. 6, 969-990 (1996).

17. D. Chopp and N. Sukumar, "Fatigue crack propagation of multiple coplanar cracks with the coupled extended finite element/fast marching method," Int. J. Eng. Sci., 41, 845-869 (2003).

18. M. Stolarska and D. L. Chopp, "Modeling thermal fatigue cracking in integrated circuits by level sets and the extended finite element method," Int. J. Eng. Sci., 41, 2381-2410 (2003).

19. G. Ventura, E. Budyn, and T. Belytschko, "Vector level sets for description of propagating cracks in finite elements," Int. J. Numer. Meth. Eng., 58, 1571-1592 (2003).

20. P. M. A. Areias and T. Belytschko, "Analysis of three-dimensional crack initiation and propagation using the extended finite element method," Int. J. Numer. Meth. Eng., 63, 760-788 (2005).

21. N. Sukumar, N. Moes, B. Moran, and T. Belytschko, "Extended finite element method for three-dimensional crack modelling," Int. J. Numer. Meth. Eng., 48, 1549-1570 (2000).

22. E. Giner, N. Sukumar, F. D. Denia, and F. J. Fuenmayor, "Extended finite element method for fretting fatigue crack propagation," Int. J. Solids Struct., 45, 5675-5687 (2008).

23. E. Budyn, G. Zi, N. Moes, and T. Belytschko, "A method for multiple crack growth in brittle materials without remeshing," Int. J. Numer. Meth. Eng., 61, 1741-1770 (2004).

24. P. Mariano and F. Stazi, "Strain localization due to crack-microcrack interactions: X-FEM for a multifield approach," Comput. Meth. Appl. Mech. Eng., 193, 5035-5062 (2004).

25. J. Bellec and J. Dolbow, "A note on enrichment functions for modelling crack nucleation," Commun. Numer. Meth. Eng., 19, 921-932 (2003).

26. N. Sukumar, D. L. Chopp, N. Moes, and T. Belyschko, "Modeling holes end inclusions by level sets in the extended finite-element method," Comput. Meth. Appl. Mech. Eng., 190, 6183-6200 (2001).

27. G. Legrain, N. Moes, and A. Huerta, "Stability of incompressible formulations enriched with X-FEM," Comput. Meth. Appl. Mech. Eng., 197, 1835-1849 (2008).

28. T. Belytschko, C. Parimi, N. Moes, et al., "Structured extended finite element methods for solids defined by implicit surfaces," Int. J. Numer. Meth. Eng., 56, 609-635 (2003). 
29. T. Nagashima, T. Omoto, and S. Tani, "Stress intensity factor analysis of interface cracks using X-FEM," Int. J. Numer. Meth. Eng., 56, 1151-1173 (2003).

30. T. Hettich and E. Ramm, "Interface material failure modeled by the extended finite-element method and level sets," Comput. Meth. Appl. Mech. Eng., 195, 47534767 (2006).

31. A. Asadpoure, S. Mohammadi, and A. Vafai, "Crack analysis in orthotropic media using the extended finite element method," Thin-Wall. Struct., 44, 1031-1038 (2006).

32. A. Asadpoure, S. Mohammadi, and A. Vafai, "Modeling crack in orthotropic media using a coupled finite element and partition of unity methods," Finite Elem. Anal. Des., 42, 1165-1175 (2006).

33. Y. Yan and S. Park, "An extended finite element method for modeling near-interfacial crack propagation in a layered structure," Int. J. Solids Struct., 45, 4756-4765 (2008).

34. E. Vitali and D. Benson, "An extended finite element formulation for contact in multi-material arbitrary Lagrangian-Eulerian calculations," Int. J. Numer. Meth. Eng., 67, 1420-1444 (2006).

35. E. Vitali and D. Benson, "Contact with friction in multi-material arbitrary Lagrangian-Eulerian formulations using X-FEM," Int. J. Numer. Meth. Eng., 76, 893-921 (2008).

36. A. R. Khoei and M. Nikbakht, "Contact friction modeling with the extended finite element method (X-FEM)," J. Mater. Process. Technol., 177, 58-62 (2006).

37. A. R. Khoei and M. Nikbakht, "An enriched finite element algorithm for numerical computation of contact friction problems," Int. J. Mech. Sci., 49, 183-199 (2007).

38. H. Chen, C. Gerlach, and T. Belytschko, "Dynamic crack growth with XFEM," in: Proc. of 6th USACM, Dearborn (2001).

39. T. Belytschko, H. Chen, J. Xu, and G. Zi, "Dynamic crack propagation based on loss of hyperbolicity and a new discontinuous enrichment," Int. J. Numer. Meth. Eng., 58, 1873-1905 (2003).

40. J. Réthoré, A. Gravouil, and A. Combescure, "An energy-conserving scheme for dynamic crack growth using the extended finite element method," Int. J. Numer. Meth. Eng., 63, 631-659 (2005).

41. T. Menouillard, J. Réthoré, A. Combescure, and H. Bung, "Efficient explicit time stepping for the extended finite element method (X-FEM)," Int. J. Numer. Meth. Eng., 68, 911-939 (2006).

42. P. Rozycki, N. Moës, E. Bechet, and C. Dubois, "X-FEM explicit dynamics for constant strain elements to alleviate mesh constraints on internal or external boundaries," Comput. Meth. Appl. Mech. Eng., 197, 349-363 (2008).

43. T. Elguedj, A. Gravouil, and A. Combescure, "Appropriate extended functions for X-FEM simulation of plastic fracture mechanics," Comput. Meth. Appl. Mech. Eng., 195, 501-515 (2006).

44. H. Hutchinson, "Singular behavior at the end of a tensile crack in a hardening material," J. Mech. Phys. Solids, 16, 13-31 (1968).

45. J. Rice and G. Rosengren, "Plane strain deformation near a crack tip in a power-law hardening material," J. Mech. Phys. Solids, 16, 1-12 (1968).

46. G. J. Wagner, N. Moës, W. K. Liu, and T. Belytschko, "The extended finite element method for rigid particles in Stokes flow," Int. J. Numer. Meth. Eng., 51, 293-313 (2001).

47. J. Chessa and T. Belytschko, "An extended finite element method for two-phase fluids," J. Appl. Mech., 70, 10-17 (2003). 
48. J. Chessa and T. Belytschko, "An enriched finite element method and level sets for axisymmetric two-phase flow with surface tension," Int. J. Numer. Meth. Eng., 58, 2041-2064 (2003).

49. S. Gro $\beta$ and A. Reusken, "An extended pressure finite element space for two-phase incompressible flows with surface tension," J. Comput. Phys., 224, 40-58 (2007).

50. A. Gerstenberger and W. A. Wall, "An extended finite element method/Lagrange multiplier based approach for fluid-structure interaction," Comput. Meth. Appl. Mech. Eng., 197, 1699-1714 (2008).

51. G. Legrain, N. Moës, and A. Huerta, "Stability of incompressible formulations enriched with X-FEM," Comput. Meth. Appl. Mech. Eng., 197, 1835-1849 (2008).

52. J. Chessa, P. Smolinski, and T. Belytschko, "The extended finite element method (XFEM) for solidification problems," Int. J. Numer. Meth. Eng., 53, 1959-1977 (2002).

53. H. Ji, D. Chopp, and J. Dolbow, "A hybrid extended finite element/level set method for modeling phase transformations," Int. J. Numer. Meth. Eng., 54, 1209-1233 (2002).

54. R. Merle and J. Dolbow, "Solving thermal and phase change problems with the extended finite element method," Comput. Mech., 28, 339-350 (2002).

55. E. Béchet, M. Scherzer, and M. Kuna, "Application of the X-FEM to the fracture of piezoelectric materials," Int. J. Numer. Meth. Eng., 77, 1535-1565 (2009).

56. S. Bordas and B. Moran, "Enriched finite elements and level sets for damage tolerance assessment of complex structures," Eng. Fract. Mech., 73, 1176-1201 (2006).

57. S. Bordas, J. G. Conley, B. Moran, et al., "A simulation based design paradigm for complex cast components," Eng. Comput., 23, 25-37 (2007).

58. I. V. Singh, B. K. Mishra, S. Bhattacharya, and R. U. Patil, "The numerical simulation of fatigue crack growth using extended finite element method," Int. J. Fatigue, 36, 109-119 (2012).

59. Abdelaziz Yazid, Nabbou Abdelkader, and Hamouine Abdelmadjid, "A state-of-theart review of the X-FEM for computational fracture mechanics," Appl. Math. Model., 33, 4269-4282 (2009).

60. A. R. Khoei, S. O. R. Biabanaki, and M. Anahid, "A Lagrangian-extended finiteelement method in modeling large-plasticity deformations and contact problems," Int. J. Mech. Sci., 51, 384-401 (2009).

61. N. Moës, M. Cloirec, P. Cartraud, and J. F. Remacle, "A computational approach to handle complex microstructure geometries," Comp. Meth. Appl. Mech. Eng., 192, 3163-3177 (2003).

62. E. E. Gdoutos, Fracture Mechanics - An Introduction, 2nd edn, Springer (2005).

63. B. N. Rao and S. Rahman, "An interaction integral method for analysis of cracks in orthotropic functionally graded materials," Comput. Mech., 32, 40-51 (2003).

64. B. Moran and C. F. Shih, "A general treatment of crack tip contour integrals," Int. J. Fracture, 27, 295-310 (1987). 